\title{
The Increasing Trend of Intense Precipitation in Japan Based on Four-hourly Data for a Hundred Years
}

\author{
Fumiaki Fujibe ${ }^{\dagger 1}$, Nobuo Yamazaki ${ }^{1}$, Mitsugi Katsuyama ${ }^{2}$ and Kenji Kobayashi ${ }^{2}$ \\ ${ }^{1}$ Meteorological Research Institute, Tsukuba, Japan \\ ${ }^{2}$ Observations Department, Japan Meteorological Agency, Tokyo, Japan
}

\begin{abstract}
Long-term changes of precipitation intensity were analyzed using a dataset which was recently compiled by the Japan Meteorological Agency (JMA). After some quality check, data of four-hourly, daily, and hourly precipitation at 46, 61, and 8 stations, respectively, were used for the period 1898-2003 on the condition that data for at least 80 years were usable in each month. As the measure of precipitation intensity, ten categories were defined so as to equate the total precipitation amount in each month at each station. The result is characterized by increase of precipitation in high categories, namely intense precipitation, and decrease in low categories. The linear trend for the highest and lowest categories is \pm 20 - $30 \%$ per century. This feature is found invariably for four-hourly, daily, and hourly precipitation, and qualitatively for all the seasons and regions.
\end{abstract}

\section{Introduction}

It is recognized in many places of the world that precipitation intensity has increased during the last century (Karl and Knight 1998; Easterling et al. 2000; IPCC 2001; Trenberth et al. 2003). Model simulations imply that the global warming results in increase of intense precipitation, although there may be differences according to regions (Semenov and Bengtsson 2002; Kitoh et al. 2004). On the local scale, the development of urban heat islands is considered to be a possible cause enhancing convective storms at cities (Landsberg 1981; Fujibe 1998).

A number of studies for Japan indicate long-term increase of intense precipitation (Iwashima and Yamamoto 1993; Kajiwara et al. 2003), although total precipitation amount has a decreasing trend over the last century. There is also some indication of multidecadal variations of precipitation intensity (Takahashi 2003; Kanae et al. 2004; Suzuki 2004). However, studies on precipitation intensity in Japan have been limited by lack of digitalized data, which are available only from 1961 for daily precipitation and from the late 1970's for hourly precipitation, except for records of extremes. Some of the studies cited above were made after great efforts to collect data from analog media such as microfilms, but there still remain a large amount of data unused, especially for the time scale shorter than a day. The situation is common to other regions of the world, where observational evidence of long-term precipitation intensity has been limited to the time scale of a day or more (IPCC 2001).

Recently, precipitation data of the Japan Meteorological Agency (JMA) were digitalized for the full period of operation, including some stations established before

Corresponding author: Meteorological Research Institute, Tsukuba 305-0052, Japan. E-mail: ffujibe@mri-jma.go.jp. @2005, the Meteorological Society of Japan.

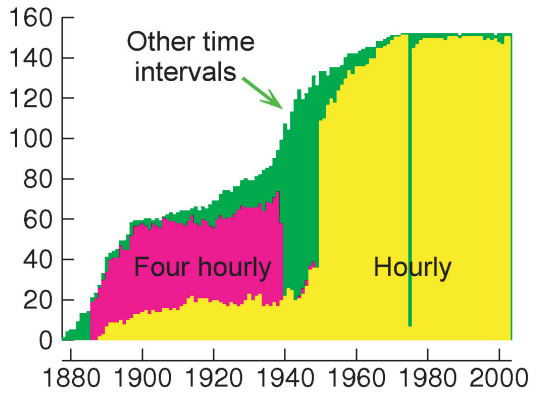

Fig. 1. Number of stations for which precipitation data are available for August, with time intervals as painted. Daily data can be obtained at all these stations.

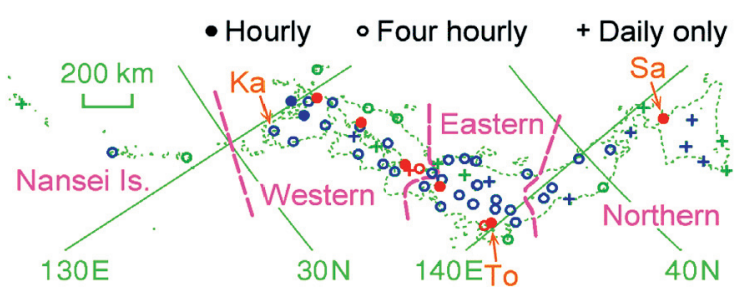

Fig. 2. Location of stations used for analysis. Fourhourly stations provide daily data, and hourly stations provide daily and four-hourly data as well. The division of the four regions used for the analysis is shown in dotted lines. Stations in large, medium-sized, and small cities, with population $\geq 10^{6}, 10^{5}-10^{6}$, and $<10^{5}$, are shown in red, blue, and green, respectively. $\mathrm{Sa}=$ Sapporo, $\mathrm{To}=$ Tokyo, and $\mathrm{Ka}=\mathrm{Kag}$ oshima.

1900. Using this dataset, which has much higher spatial and temporal coverage than the one used in previous studies, we aim at evaluating the precipitation changes during the last hundred years in Japan, with focus on the long-term changes of precipitation intensity.

\section{Data}

Figure 1 shows the number of stations for which precipitation records are available, for August as an example. Note that part of the data were judged "unusable" as described later in this section. Until the 1930's, precipitation observation in Japan was made every four hours (02, 06, ---, 22 JST), except for some stations of hourly and other observation intervals. The 1940's and the 1950's are a period of complication, including non-uniform observation time (for example, 06, 12, 14, 18, and 

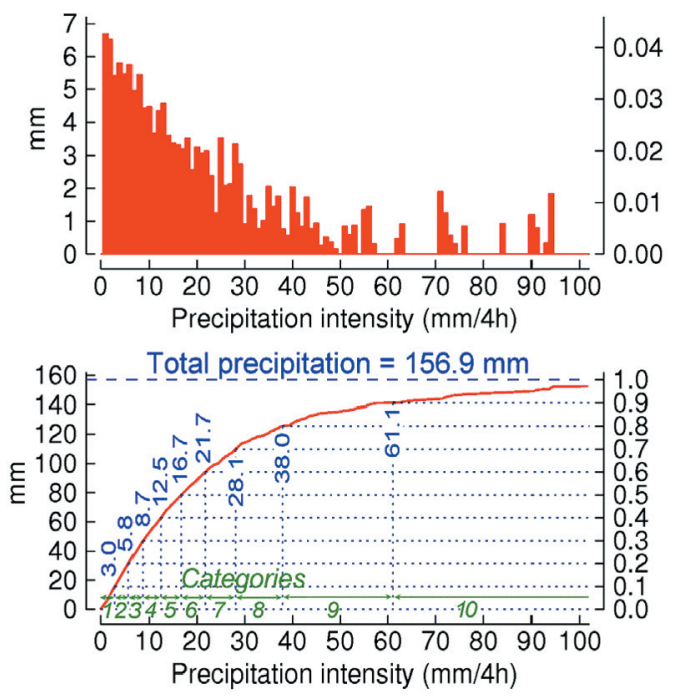

Fig. 3. Definition of intensity categories for four-hourly precipitation at Tokyo in August as an example. The upper panel shows the monthly precipitation amount (average for 1898-2003) in each $1 \mathrm{~mm} / 4 \mathrm{~h}$ interval, and the lower panel shows its integration, namely the cumulative precipitation amount. The scale on the left gives precipitation amount, and that on the right indicates relative amount with respect to the total.
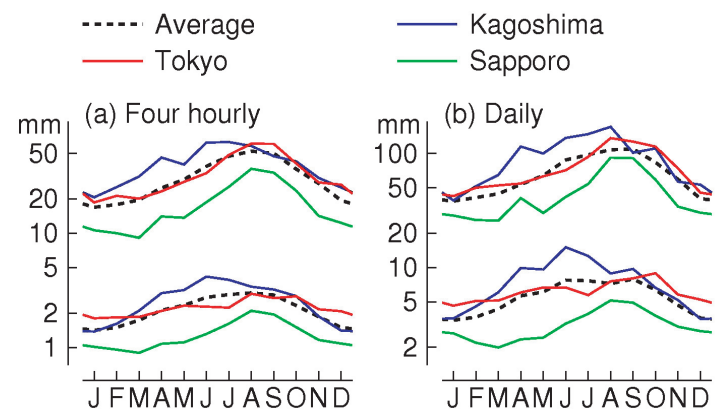

Fig. 4. Annual variations of the upper boundary of the lowest category, and the lower boundary of the highest category.

22 JST) and three- or six-hourly observations, although hourly data are available at many stations after 1950. After 1960, hourly data can be obtained at most of the stations. These data have been digitalized from microfilms in the Observations Department of the JMA, to add to already digitalized data of daily precipitation from 1961 and the hourly AMeDAS data from the late 1970's.

As seen from Fig. 1, the number of stations increased by the end of the 19th century. Therefore the year of 1898 was chosen as the starting point of the analysis, with the ending year as 2003. The analysis was made for four-hourly precipitation in the main, and for daily and hourly precipitation as supplements. Data of other observation intervals were not used.

Until 1967, precipitation observation was made with conventional cylinder-type raingauges and siphon raingauges with resolution of $0.1 \mathrm{~mm}$. Since 1968, the tipping bucket raingauge has been used with resolution of $0.5 \mathrm{~mm}$. The hourly AMeDAS data are recorded in the $1 \mathrm{~mm}$ resolution from 1976 to 1994. In order to avoid the bias due to the differences in observation resolution, all the data were reduced to the resolution of $1 \mathrm{~mm}$. The tipping bucket raingauge incrementally measures the precipitation accumulation, so that precipitation of 4.3 $\mathrm{mm}$, for example, will be measured to be $4 \mathrm{~mm}$ at the $70 \%$ probability and $5 \mathrm{~mm}$ at the $30 \%$ probability in the observation of $1 \mathrm{~mm}$ resolution, depending on the initial water content in the bucket. Reduction to the $1 \mathrm{~mm}$ resolution was made by applying these probabilities as weights to the neighboring integer values. For example, a record of $4.3 \mathrm{~mm}$ was treated as a $4 \mathrm{~mm}$ record with a weight of 0.7 and a $5 \mathrm{~mm}$ record with a weight of 0.3 .

Since the quality of the digitalized data is not perfect, a rough error check and correction, if possible, were made. Error data tend to cluster in a limited period, often mixed in many missing data. By checking each month at each station, the data therein were regarded as unusable if there were more than three missing or doubtful records in any one of the observation times of the day. Otherwise the data in the month were weighted so as to compensate for the loss due to missing and doubtful records. For example, if there were four missing records at 02 JST in a month, then all the data in the month at the station were not used for analysis, even if there were no missing record at other observation times. If there were two missing records at 02 JST and three at 10 JST in the four-hourly analysis, then the remaining records, which were $181(31 \times 6-5)$ in number if it was a month of 31 days, were each counted as representing $186 / 181=1.028$ cases.

After these procedures, stations were selected on the condition that data for at least 80 years, including three among the first five years of the analysis (1898-1902), were usable for each month. The resulting number of stations is 46,61 , and 8 for four-hourly, daily, and hourly precipitation, respectively. Figure 2 shows the location of these stations.

\section{Definition of precipitation categories}

The analysis is based on ten intensity categories, which were defined so as to equate the monthly precipitation amount averaged for the analysis period (18982003), as described in Fig. 3 for August at Tokyo as an example. In this example, the average precipitation in August is $156.9 \mathrm{~mm}$, which is contributed by ten categories with equal weight $(15.69 \mathrm{~mm})$. The ranges of the categories are $<3.0 \mathrm{~mm} / 4 \mathrm{~h}, 3.0-5.8 \mathrm{~mm} / 4 \mathrm{~h}, \cdots, \geq 61.1$ $\mathrm{mm} / 4 \mathrm{~h}$, which were determined from the cumulative precipitation amount (lower panel of Fig. 3) based on linear interpolation between each $1 \mathrm{~mm}$ interval.

The ranges of categories differ according to months and stations. Figure 4 shows the annual variations of the upper boundary of the lowest category (category 1), and the lower boundary of the highest category (category 10) for Sapporo, Tokyo, Kagoshima, and the average over all the stations. The lowest category for fourhourly precipitation is below $1-3 \mathrm{~mm} / 4 \mathrm{~h}$, and the highest category is above $10-50 \mathrm{~mm} / 4 \mathrm{~h}$. For daily precipitation, the lowest category is below $2-10 \mathrm{~mm} /$ day, and the highest category is above $30-150 \mathrm{~mm} /$ day.

The regional and annual (or seasonal) average precipitation in the category $r$ is defined by

$$
P_{n r}=\sum_{i, m} p_{n m i r} / N_{n}
$$

where $p_{\text {nmir }}$ is the precipitation amount in the category $r$ at the station $i$ in the month $m$ in the year $n$, and $N_{n}$ is the number of months in the summation. It is to be 


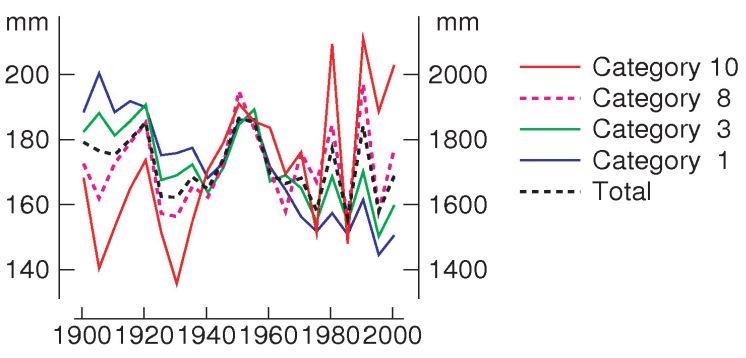

Fig. 5. Time series of precipitation amount (five-year average for all the stations) in categories $1,3,8$, and 10 (namely, $P_{n r}$; left scale) and the total precipitation (namely, $\bar{P}_{n}$; right scale).

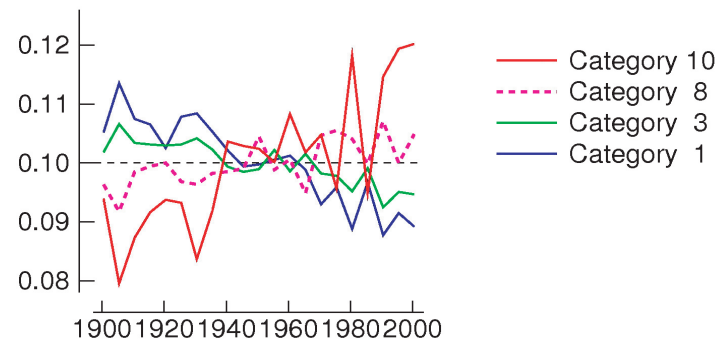

Fig. 6. Same as Fig. 5, but for relative values with respect to the total precipitation (namely, $P_{n r}^{\prime}$ ).

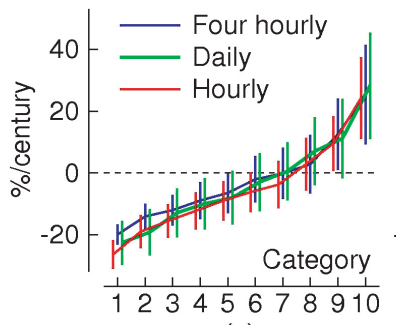

(a)

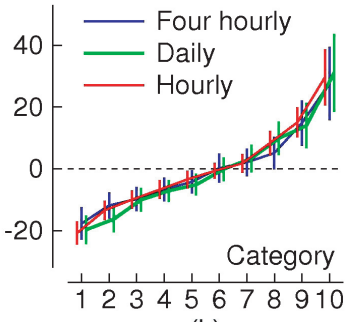

(b)
Fig. 7. Linear trends of precipitation, namely, (a) $B_{r}$ and (b) $b_{r}$ for each category (annual average for all the stations). Vertical bars indicate the 95\% confidence range.

noted that the linear interpolation of cumulative precipitation amount (lower panel of Fig. 3) is equivalent to assume a uniform frequency distribution in each $1 \mathrm{~mm}$ interval. If the interval spans over more than one category, then the precipitation amount therein must be assigned to $p_{\text {nmir }}$ in each category in proportion to its coverage. For example, precipitation of $4 \mathrm{~mm}$ was regarded as representing the precipitation from $3.5 \mathrm{~mm}$ to $4.5 \mathrm{~mm}$ with uniform weight, and if there are two categories bounded at $3.8 \mathrm{~mm}$, then $(3.8-3.5) \times 4 \mathrm{~mm}=1.2 \mathrm{~mm}$ was assigned to the lower category and the remaining $2.8 \mathrm{~mm}$ was assigned to the higher category. The total precipitation amount is given by

$$
\bar{P}_{n}=\sum_{r} P_{n r} \text {. }
$$

\section{Results}

Figure 5 shows the changes of five-year mean precipitation amount (six-year mean for the first period, namely 1898-1902) averaged over the whole area, obtained from the four-hourly precipitation. The variation of the total precipitation amount basically agrees with the JMA (1999) with respect to a relatively large amount in the 1940's and a small amount in the recent decades during the hundred years. The linear trend over the whole period is $-7.6 \pm 6.6 \%$ per century, in rough agreement with that evaluated by the JMA (1999; $-6.6 \pm 6.0 \%$ per century). The variation of precipitation amount in each category is more or less in phase with the total precipitation, while there is a relative decreasing trend in the low categories and an increasing trend in the high categories. In order to isolate the relative changes among categories, the long-term variation of the percentage of precipitation amount in each category, defined by $P_{n r}^{\prime}=P_{n r} / P_{n}$, is shown in Fig. 6. The opposite trends of lower and higher categories are clearly seen.

Figure 7 a shows the linear trend of $P_{n r}$ as a function of the category number, not only for four-hourly precipitation but also for daily and hourly precipitation. The linear trend was obtained from the least-squares condition

$$
\sum_{n} N_{n}\left[P_{n r}-\left\{A_{r}+B_{r}\left(n-\frac{n_{1}+n_{2}}{2}\right)\right\}\right]^{2} \rightarrow \min .,
$$

where $n_{1}$ and $n_{2}$ are the first and the last year of the analysis period (namely, 1898 and 2003), and $A_{r}$ and $B_{r}$ are the least-squares coefficients indicating the longterm mean and the trend, respectively. The weight $N_{n}$ was assigned in order to suppress the influence of some years for which data were scarce (such as the 1940's). The three graphs in Fig. 7a are very close to one another, each characterized by a monotonous increase toward higher categories. The trend of the lowest category, namely $B_{1}$, is $-26.4 \pm 2.4 \%,-19.9 \pm 1.7 \%$, and $-22.6 \pm$ $3.6 \%$ per century for four-hourly, daily, and hourly precipitation, respectively. The trend of the highest category, $B_{10}$, is $24.1 \pm 6.7 \%, 25.4 \pm 8.2 \%$, and $28.2 \pm 8.8 \%$ per century, respectively.

Figure $7 \mathrm{~b}$ shows the linear trend of $P_{n r}^{\prime}$ obtained from the least-squares condition

$$
\sum_{n} \bar{P}_{n}\left[P_{n r}^{\prime}-\left\{a_{r}+b_{r}\left(n-\frac{n_{1}+n_{2}}{2}\right)\right\}\right]^{2} \rightarrow \min .,
$$

where the weight $\bar{P}_{n}$ was assigned for the same reason as in (3). The trend of the lowest category, namely $b_{1}$, is $-20.8 \pm 1.9 \%,-17.7 \pm 2.7 \%$, and $-19.7 \pm 2.3 \%$ per century, and that of the highest category, $b_{10}$, is $29.6 \pm 4.6 \%, 27.8 \pm 6.1 \%$, and $31.0 \pm 6.4 \%$ per century, respectively. The differences between Figs. $7 a-b$, corresponding to the trend of the total precipitation, are much smaller than the trends of the lowest and highest categories.

As seen from Fig. 6, the time series of $P_{n r}^{\prime}$ is characterized by a continuous change during the analysis period. Figure 8 a shows the linear trends $\left(b_{r}\right)$ obtained for the former and latter halves of the analysis period, as well as for the whole period. The negative and positive trends of low and high categories are common to the two periods.

It is to be noted that a single station may exhibit a more complicated change of precipitation intensity. For example, intense precipitation at Tokyo has been found to show a large variation on the multi-decadal scale (Takahashi 2003; Kanae et al. 2004). In agreement with this, the value of $P_{n}^{\prime}, 10$ at Tokyo has maxima of $0.14-$ 


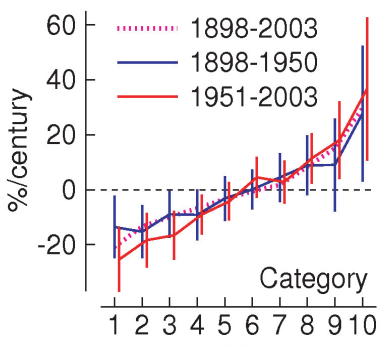

(a)

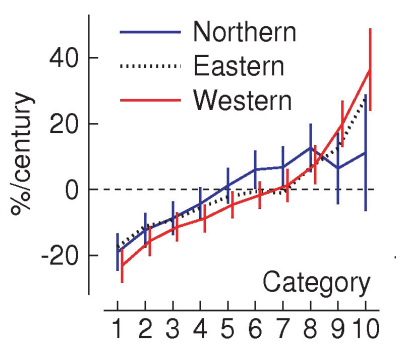

(c)

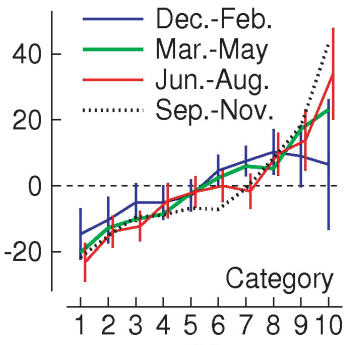

(b)

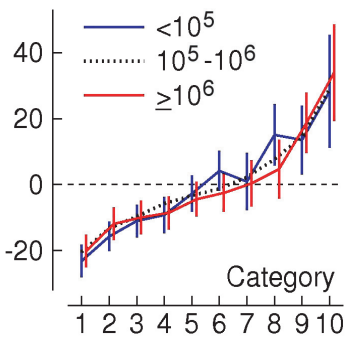

(d)
Fig. 8. Linear trends $\left(b_{r}\right)$ of four-hourly precipitation for (a) each analysis period, (b) each season, (c) each region, and $(\mathrm{d})$ each population range of cities and towns where the stations are located (see Fig. 2). Confidence ranges are presented for items shown in red and blue lines.

0.15 around 1940 and 2000, and a minimum of 0.06 in the 1970's (not shown), although a linear regression over the whole period yields a positive trend of $48 \%$ per century. Thus the continuous change in Fig. 6 is a regionally averaged feature, which may be difficult to detect in the analysis for a small number of stations.

Figures $8 \mathrm{~b}-\mathrm{c}$ show the comparison among seasons and regions, respectively. The increasing trend of heavy precipitation is weaker in winter than in other seasons, and in the northern part of Japan than in other regions. Qualitatively, however, the differential changes between low and high categories are found for all of the four seasons and the three regions. Also, such changes are commonly found for the southeastern and the northwestern sides of the Japanese islands, and for inland and coastal stations (not shown).

Figure 8d shows the comparison with respect to the population of cities and towns where the stations are located, on the basis of the 2000 census. There is a little difference in the trends of four-hourly precipitation among large, medium, and small cities.

\section{Remarks}

The present study reconfirmed the differential precipitation trends in Japan, characterized by increase of intense precipitation and decrease of weak precipitation, using a larger number of stations and shorter-term precipitation (four hourly and hourly) than in previous studies. The trend during the analysis period is approximately constant (Figs. 6 and 8a), which tacitly ensures the absence of bias due to changes in observational equipments and resolution.

An interesting feature is the qualitative similarity of results throughout the year and over the whole area (Fig. 8b-c), in spite of the large seasonal and regional differences in the predominant circulation patterns. This fact implies that the trends reflect a change in the general environment for precipitation activity, rather than some changes specific to a season or a region (such as changes in the monsoon circulations or typhoon activities). It is possible that the global warming and increase of water vapor result in increase of localized, intense precipitation.

A signal of urban effect is not detectable in our result (Fig. 8d), in which intense precipitation has increased not only at large cities but also at small cities and towns. However, this does not deny the possible influence of urbanization on precipitation. The majority of heavy rainfall events in Japan are caused by largescale convective systems, while urban influence is believed to be enhanced for localized, short-term precipitation under sunny and undisturbed weather. A more detailed and careful analysis is needed to evaluate urban anomaly in intense precipitation.

\section{References}

Easterling, D. R., G. A. Meehl, C. Parmesan, S. Changnon, T. R. Karl, and L. O. Mearns, 2000: Climate extremes: Observations, modeling and impacts. Science, 289, 2068-2074.

Fujibe, F., 1998: Spatial anomalies and long-term changes of precipitation in Tokyo. Tenki, 45, 7-18 (in Japanese with English abstract).

IPCC, 2001: Climate change 2001: The scientific basis. Contribution of Working Group I to the third Assessment Report of the IPCC [Houghton, J. T. et al. (eds.)]. Cambridge University Press, $881 \mathrm{pp}$.

Iwashima, T., and R. Yamamoto, 1993: A statistical analysis of the extreme events: Long-term trend of heavy daily precipitation. J. Meteor. Soc. Japan, 71, 637-640.

JMA, 1999: Reports on recent climate change in the world (VI). JMA, $341 \mathrm{pp}$ (in Japanese).

Kajiwara, M., T. Oki and J. Matsumoto, 2003: Secular change in the frequency of heavy precipitation over Japan for 100 years. Proceedings of the 2003 Spring Meeting of the MSJ, 484 (in Japanese).

Kanae, S., T. Oki and A. Kashida, 2004: Changes in hourly heavy precipitation at Tokyo from 1890 to 1999. J. Meteor. Soc. Japan, 82, 241-247.

Karl, T., and R. W. Knight, 1998: Secular trends of precipitation amount, frequency, and intensity in the United States. Bull. Amer. Meteor. Soc., 79, 231-241.

Kitoh, A., M. Hosaka, Y. Adachi and Y. Murata, 2004: Changes of precipitation characteristics by global warming simulated by the MRI CGCM. 15th Symposium on Global Change and Climate Variations, AMS, Seattle, January 2004.

Landsberg, H. E., 1981: The urban climate. Academic Press, 275 pp.

Semenov, V. A., and L. Bengtsson, 2002: Secular trends in daily precipitation characteristics: Greenhouse gas simulation with a coupled AOGCM. Clim. Dyn., 19, 123-140.

Suzuki, H., 2004: Trend in the frequency of heavy rainfall events during the last half century over Japan. Tenki, 51, 805-816 (in Japanese with English abstract).

Takahashi, H., 2003: Secular variation in the occurrence property of summertime daily rainfall amount in and around the Tokyo Metropolitan area. Tenki, 50, 31-41 (in Japanese with English abstract).

Trenberth, K. E., A. Dai, R. M. Rasmussen, and D. B. Parsons, 2003: The changing character of precipitation. Bull. Amer. Meteor. Soc., 84, 1205-1217.

(Manuscript received 24 December 2004, accepted 1 March 2005) 